\title{
Macroamylasemia: A rare diagnosis
}

\author{
Nadir bir tanı: Makroamilazemi \\ Alihan Oral(1), Aysu Akin (i), Fatih Türker (D), Aydın Tunçkale (1) \\ Department of Internal Medicine, Istanbul Bilim University, Faculty of Medicine, Istanbul, Turkey
}

Elevated amylase levels are most commonly observed in acute pancreatitis and pathologies involving the salivary glands. While amylase levels reach its peak in the initial hours of acute pancreatitis, it is expected to return to normal within one week of treatment. When hyperamylasemia is encountered, pancreas-related pathologies should be primarily considered. However, elevated amylase may also occur in many pathological and non-pathological conditions. Aside from the pancreatic pathologies, hyperamylasemia can also be detected in salivary gland pathologies, chronic alcoholism, lactic acidosis, postoperative stress, anorexia nervosa, diabetes, bulimia, and

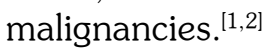

Although elevated blood enzyme levels are generally pathological, sometimes the condition of macroenzymes can be encountered. ${ }^{[3]}$ Macroamylasemia occurs as a result of amylase complexing with immunoglobulin. ${ }^{[4]}$ Macroamylasemia is generally prevalent in about $1 \%$ of the population and is often overlooked. ${ }^{[3,5]}$ This report presents a case of asymptomatic hyperamylasemia.

A 55-year-old woman followed up with the diagnosis of generalized anxiety disorder presented to our emergency department with drowsiness and agitation. Her tests revealed amylase: $1650 \mathrm{U} / \mathrm{L}$, while lipase and other parameters were normal. The patient was taking $200 \mathrm{mg}$ quetiapine, $60 \mathrm{mg}$ duloxetine, and $10+10 \mathrm{mg}$ hyoscine-n-butylbromide medazepam hydrochloride. Aside from anxiety, the patient had no other history of chronic disease. Upon physical examination, the patient was in good general condition, conscious, cooperative, and oriented; her abdomen was relaxed with no rebound or guarding. Ultrasound showed no signs other than hepatosteatosis. Pancreatitis was ruled out. Parotid ultrasound was performed and salivary gland pathology was ruled out. No other physical examination or laboratory finding suggesting other causes of elevated amylase could be found. Since the patient's amylase value did not decrease during follow-up, in order to determine amylase-creatinine clearance ratio, amylase and creatinine levels were studied in urine and serum. Urine amylase was $412 \mathrm{IU} / \mathrm{L}$, serum amylase $637 \mathrm{IU} / \mathrm{L}$, urine creatinine $263.2 \mathrm{mg} / \mathrm{dL}$, serum creatinine was $0.9 \mathrm{mg} / \mathrm{dL}$; amylase-creatinine clearance ratio was $0.23 \%$ (reference interval: $1.8-3.2 \%$ ), which was interpreted in favor of macroamylasemia.

Since the pancreas and salivary glandrelated pathologies were ruled out and amylase-creatinine clearance rate was low, the 
patient's hyperamylasemia was diagnosed as macroamylasemia. In patients with asymptomatic isolated hyperamylasemia, macroamylasemia should come to mind.

\section{Declaration of conflicting interests}

The authors declared no conflicts of interest with respect to the authorship and/or publication of this article.

\section{Funding}

The authors received no financial support for the research and/or authorship of this article.

\section{REFERENCES}

1. Pieper-Bigelow $C$, Strocchi A, Levitt MD. Where does serum amylase come from and where does it go? Gastroenterol Clin North Am 1990;19:793-810.

2. Clink D, Weaver D, Bouwman D, Sessions S, Stephany J. Clinical application of organ specific isoamylases. Am Surg 1982;48:422-5.

3. Türkçapar N, Özden A. Macroenzymes. Güncel Gastroenteroloji 2005;9:161-6.

4. Goldberg DM, Spooner RJ. Amylase, isoamylase and macroamylase. Digestion 1975;13:56-75.

5. Galasso PJ, Litin SC, O'Brien JF. The macroenzymes: a clinical review. Mayo Clin Proc 1993;68:349-54. 